\title{
Coordinated Development between Assistance to Tibet and Tourism Development: Spatial Patterns and Influencing Factors
}

\author{
Song Liu $\mathbb{D}$, ${ }^{1}$ Xia Xie $\mathbb{D}^{2,3}$ Xiaofei Zhang $\mathbb{D}^{1},{ }^{1}$ Chunshan Zhou $\mathbb{D}^{1,2,3}$ and Yonglong Cai ${ }^{4}{ }^{4}$ \\ ${ }^{1}$ School of Geography and Planning, Sun Yat-Sen University, Guangzhou 510275, China \\ ${ }^{2}$ Key Laboratory of the Sustainable Development of Xinjiang's Historical and Cultural Tourism, Xinjiang University, \\ Urumqi 830046, China \\ ${ }^{3}$ College of Tourism, Xinjiang University, Urumqi 830049, China \\ ${ }^{4}$ School of Geography, Faculty of Geographical Science, Beijing Normal University, Beijing 100875, China
}

Correspondence should be addressed to Xia Xie; xiexia919@163.com

Received 1 August 2020; Accepted 24 September 2020; Published 16 October 2020

Academic Editor: Lifei Chen

Copyright (c) 2020 Song Liu et al. This is an open access article distributed under the Creative Commons Attribution License, which permits unrestricted use, distribution, and reproduction in any medium, provided the original work is properly cited.

The Chinese government has provided various forms of assistance to the Tibet Autonomous Region and has substantially improved their facilities, which has had a positive influence on the development of tourism in Tibet. The present study investigated how assistance to Tibet (AT) coordinates with tourism development (TD) by exploring the patterns and influencing factors of AT and TD using statistical data from 74 prefectural units from 1991 to 2015. The findings led to several conclusions: (1) AT displayed strong and constant coupling interactions with TD, and the coupling coordination degree increased from moderately unbalanced development (MUD) to barely balanced development (BBD). However, the coupling coordination degree remains low (MUD) in most prefectural units; (2) in 2015, the degree of coupling coordination displayed a "core-periphery" spatial pattern (i.e., low in center and high in the periphery), which highly coincides with the patterns of AT $(x)$ and TD $(y)$, and should thus be improved further; and (3) both AT factors and TD factors have significant effects on the spatial differentiation of coupling coordination degree but not on the coupling degree. This study expands research on coupling coordination and AT and provides scientific guidance for further coordinating AT and TD.

\section{Introduction}

Since the reform and opening-up, China's economic growth has adopted a "two-step" strategy based on the unbalanced growth and balanced growth theories [1]. From 1978 to the early 1990s, China implemented an unbalanced development strategy that prioritized the eastern region. From the early 1990s to the beginning of the twenty-first century, China continued the unbalanced development strategy that prioritized the development of the eastern region, but also considered the central and western regions (Western development strategy, 2000; Rise of Central China Plan, 2004). After the early twenty-first century, a balanced and coordinated development strategy was implemented [2, 3]. Under the unbalanced development strategy, the regional disparity of China's economy grew in the eastern, central, and western regions [4]; therefore, promoting the coordinated development of western regions, especially the marginal areas, is crucial.

Assistance to Tibet (AT) refers to the sum of assistance received by the Tibet Autonomous Region, which is a system of economic assistance (e.g., finance and funds), projects, talent, education, and technical assistance [5]. AT is regarded as a systematic project. AT is a valuable means of macrocontrol by the Chinese government by promoting Tibet's socioeconomic development through the reallocation of assistance resources to reduce the regional gaps and promote the coordinated development of Tibet [6].

Tibet Autonomous Region, which is located in marginal China, has been in an inferior position in terms of the national economic pattern since 1951 [7]. CPC Central Committee provided various forms of assistance and held six 
"Work Forum on Tibet" (WFT) [8], which promoted the socioeconomic development of Tibet. However, tourism development (TD) in Tibet has not garnered sufficient attention, and the AT prioritizes urban development and livelihood improvement projects rather than tourism [6], which caused the decoupling of TD and AT. Moreover, AT also caused regional inequalities within Tibet because of imbalances and reallocation of assistance $[6,9]$. Therefore, coordinating the development of AT and TD in Tibet was addressed.

After the third WFT (1994), tourism assistance increased [10]. Tourism in Tibet became a dominant sector in the tertiary industry, accounting for $61 \%$ of tertiary industry output in 2019 (9\% in 1994). A further increase in assistance was proposed in the sixth WFT (2015), which also provided the opportunity for TD. Investigating the coupling relationships between AT and TD could provide further development guidance.

Therefore, the present study focused on the coordination of AT with TD by exploring the types, spatial distributions, and influencing factors of coordinated development of AT and TD, using statistical data from 74 prefectural units in Tibet from 1991 to 2015.

Coupling is a widespread method to evaluate the interrelationships between systems or geographical features and aspects, such as economic development (ED), urbanization (UR), eco-environment (ECE), resource utilization (RU), and land use (LU), in China. In the late 1990s to early 2000s, as eco-environment topics emerged because of the rapid development of the economy and urbanization, scholars began exploring the coupling relationship between ED and ECE, as well as UR and ECE, to enable coordinated and sustainable development $[11,12]$. From 2010 to 2020, the eco-environment has received increasing attention by the Chinese government, and research on the coupling coordination of ECE and ED, as well as ECE and UR, is becoming increasingly popular and crucial topics in coupling coordination research [13-16]. The coupling coordination relationship of UR and LU is also an increasingly popular and vital topic. Land-use efficiency and the intensive use of land are especially emphasized [17-19]. Moreover, the coupling relationship between RU and UR, RU and ECE, and LU and ECE are also regarded as critical topics to be discussed [20-22]. Moreover, numerous new studies have investigated the coupling coordination relationships between ED, UR, ECE, RU, and LU and geographical features (such as carbon emission, environment carrying capacity, infrastructural development, tourism development, livelihood level, and rural hollowing, respectively) [23-28].

China's socioeconomic diversification in the 2000s and 2010s led to contradictions to development that are not limited to ED, UR, ECE, RU, and LU, but also extend to the diverse geographical features, which are also extensively investigated [29-32].

For example, scholars have discussed the coordination of the population, economic, social, and spatial urbanization $[33,34]$, whereas others have discussed the coupling relationships between multidimensional urbanization and the service industry $[35,36]$. Urbanization and economic, ecological, and transportation improvement have been demonstrated to have coupling relationships with TD. Urbanization improves several factors that are crucial in tourism, such as infrastructure, products, services, and image [37, 38]; the regional economy increases the disposable income of households and improves the tourism infrastructure by increasing investments [39, 40]; the ecological environment provides tourists with authentic tourism products [41, 42]; transportation improves tourism accessibility [43-45]. These factors promote tourism by accelerating the growth of related industries.

AT has high coupling relationships with ED and UR in Tibet. However, the coordinated development level is still low and spatially varied $[5,46]$. The results indicate that AT is vital to Tibet and should be further intensified.

Previous studies are focused on "what is AT?" "why is AT important?" and "how can AT be improved?" For the first question, scholars are concerned about where AT systems originate and how they evolve [47, 48]. Scholars have concluded that AT originates from first-generation Chinese national leaders who strived for the equal development of Tibet by implementing the assistance strategy [49]. The evolution of "strategy to system" focuses on the economy, staff, education, and techniques [50] developed by five generations of national leaders [51]. For the second question, studies have determined that AT promoted the socioeconomic development of Tibet [52] and changed the industry structure [53]. Furthermore, AT strengthened the atypical dual economic structure of Tibet society [54]. For the third question, findings have emphasized that improving Tibet's self-development ability is crucial [55]. Promoting the effectiveness and reallocation of AT is also vital $[6,9]$. Furthermore, tourism assistance was analyzed [56, 57]. The TD in Tibet and literature on the exploitation of tourism resources and tourism-related industries were discussed $[58,59]$.

The aforementioned studies have investigated the development of AT and TD. However, the coordinated development in coupling relationships between AT and TD warrants further investigation.

To bridge the gap in knowledge, we suggested that the coupling relationship and coordinated development of AT and TD should be considered when exploring the development of AT and TD in Tibet.

The present study aims to fulfill the three objectives to reduce the economic gap: first, the temporal changes and spatial distribution characteristics of the coupling and coordination of AT and TD are assessed; second, the coupling coordination patterns of AT and TD and their distribution in space are assessed; third, the influencing factors on the spatial distribution of the coupling and coordination degree are assessed.

The findings will contribute to the theoretical knowledge on the relationships between AT and TD.

\section{Study Area}

Tibet has 74 prefectural units that are divided into four landform regions by several huge mountains: the Northern Tibetan plateau region (TPR), the Southern Brahmaputra 
river basin region (BRBR), the eastern alpine valley region (AVR), and the Himalayan mountain region (HMR).

The "Yijiangsihe" region-the Brahmaputra River, the Nianchu River, the Lhasa River, the Yalong River, and the Niyang River-is located in the BRBR, which is the center of population, economy, and culture in Tibet, and has a relatively high socioeconomic development level and numerous scenic spots. The marginal regions-the TPR, AVR, and HMR - have relatively low socioeconomic development levels and fewer scenic spots.

The scenic spots present a "core-periphery" spatial pattern (Figure 1).

\section{Materials and Methods}

3.1. Evaluation Index System. An AT evaluation index system, with five second-class indicators within the first-class indicators of financial assistance, infrastructure development, and public service development, was adopted based on previous studies [5, 42]. An evaluation index system of TD, with 11 second-class indicators under the first-class indicators of tourism economic environment, tourism social benefits, tourism economic benefits, and tourism development vitality, was adopted (Table 1).

3.2. Data Collection and Preprocessing. The time-series data (from 1991 to 2015) and the cross-sectional data (74 prefectural units) of AT and TD were collected separately from the Tibet County Survey, Tibet Statistical Yearbook, Tibet Yearbook, and the Fifth and Sixth Batch of AT.

To eliminate bias caused by the difference of dimension and magnitude, the min-max normalization was utilized. For positive indices, the calculation is as follows [60]:

$$
X_{i j}^{\prime}=\frac{X_{i j}-\min _{1 \leq j \leq n} X_{i j}}{\max _{1 \leq j \leq n} X_{i j}-\min _{1 \leq j \leq n} X_{i j}},
$$

whereas for negative indices, the calculation is as follows:

$$
X_{i j}^{\prime}=\frac{\max _{1 \leq j \leq n} X_{i j}-X_{i j}}{\max _{1 \leq j \leq n} X_{i j}-\min _{1 \leq j \leq n} X_{i j}},
$$

where $X_{i j}^{\prime}$ and $x_{\mathrm{ij}}$ represent the standardized value and the original value of index $j$ in year and unit $i$, respectively; $\max _{1 \leq j \leq n} X_{i j}$ and $\min _{1 \leq j \leq n} X_{i j}$ indicate the maximum and minimum value of index $j$ among all years and units, respectively.

If $x_{1}, x_{2}, \ldots, x_{p}$ represent the indices of AT and $y_{1}, y_{2}, \ldots$, $y_{q}$ represent the indices of $\mathrm{TD}$, then

$$
\begin{aligned}
& \operatorname{AT}(x)=\sum_{t=1}^{p} w_{t} x_{t}^{\prime}, \\
& \operatorname{TD}(y)=\sum_{e=1}^{q} w_{e} y_{e}^{\prime},
\end{aligned}
$$

where $\mathrm{AT}(x)$ and $\mathrm{TD}(y)$ are the integration values of $\mathrm{AT}$ and $\mathrm{TD}$, respectively; $\eta=\mathrm{AT}(x) / \mathrm{TD}(y)$ is the relative development degree of AT and TD [61], and AT $(x)<\mathrm{TD}(y)$ $(0<\eta<0.80)$ indicates that the integration value of $\mathrm{AT}$ is smaller than that of TD (i.e., AT-lagged type); AT $(x)=\mathrm{TD}$ (y) $(0.80<\eta<1.20)$ indicates that the integration value of AT is equal to that of TD (i.e., AT and TD synchronized type); $\operatorname{AT}(x)<\mathrm{TD}(y)(\eta>1.20)$ indicates that integration value of AT is larger than that of TD (i.e., TD-lagged type); $x_{t}^{\prime}$ and $y_{e}^{\prime}$ are the standardized value of $x_{\mathrm{t}}$ and $y_{\mathrm{e}}$, respectively, which can be calculated using $X_{i j}^{\prime}$ in formulas (1) and (2); $w_{t}$ and $w_{e}$ are the weight of $x_{\mathrm{t}}$ and $y_{\mathrm{e}}$, respectively, which can be calculated using information entropy weight (IEW).

IEW has been employed in studies evaluating the status uncertainty of the system [14]. The index weight can be determined by analyzing the correlation and information among the indices, which avoids bias caused by subjective preferences and guarantees objectivity. Steps are as follows [41]:

(1) Calculating the proportion of the index $j$ in year/unit $i\left(\mathrm{R}_{\mathrm{ij}}\right)$

$$
R_{i j}=\frac{X_{i j}^{\prime}}{\sum_{i=1}^{m} X_{i j}^{\prime}} .
$$

(2) Calculating the information entropy of the index $j$ $\left(e_{\mathrm{j}}\right)$

$$
e_{j}=-\frac{1}{\ln m} \sum_{i=1}^{m} R_{i j} \times \ln R_{i j}
$$

(3) Calculating the weight of the index $j\left(w_{j}\right)$

$$
w_{j}=\frac{1-e_{j}}{\sum_{j=1}^{n}\left(1-e_{j}\right)},
$$

where $n$ is the number of indexes and $m$ is the number of years or units.

\subsection{Calculating the T, C, and D of AT and TD}

3.3.1. Calculating the Comprehensive Development Degree of $A T$ and TD. To evaluate the comprehensive development degree (T) of AT and TD, the formula is as follows [41]:

$$
T=\alpha \times \operatorname{AT}(x)+\beta \times \operatorname{TD}(y),
$$

where $T$ reflects the comprehensive development degree of $\mathrm{AT}$ and TD; $\alpha$ and $\beta$ represent the contribution of AT and $\mathrm{TD}$, respectively. AT is vital for the development of Tibet, and thus the values of $\alpha$ and $\beta$ are $2 / 3$ and $1 / 3$, respectively [5]. The evaluation grade of $T$ is set up into four grades [62] (Table 2).

3.3.2. Calculating the Coupling Coordination Degree. Coupling refers to the motion of the system, whereby the subsystems interact with each other. Coordination refers to 


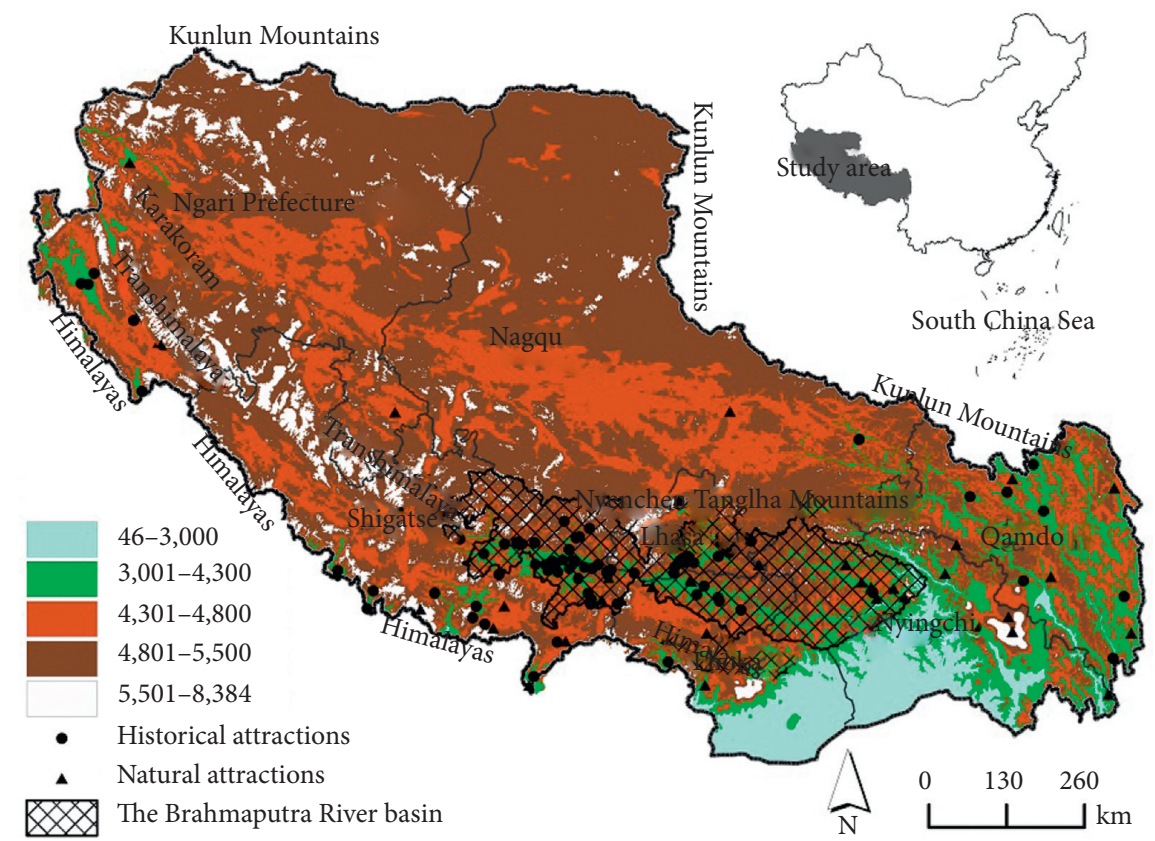

FIgURE 1: Study area.

TABle 1: Evaluation index system of AT and TD.

\begin{tabular}{|c|c|c|c|c|}
\hline Variables & First-class indicator & Second-class indicator and direction & Notation & Unit \\
\hline \multirow{5}{*}{$\begin{array}{l}\text { Assistance to Tibet AT } \\
(x)\end{array}$} & Financial assistance (FS) & Fiscal transfer payment $(+)(x 1)$ & FTP & $\begin{array}{c}10,000 \text { million } \\
¥ \neq\end{array}$ \\
\hline & \multirow{2}{*}{$\begin{array}{l}\text { Infrastructure development } \\
\text { (ID) }\end{array}$} & $\begin{array}{c}\text { Ratio of infrastructure investment to fixed asset } \\
\text { investment }(+)(x 2)\end{array}$ & RIIFAI & $\%$ \\
\hline & & Density of road network $(+)(x 3)$ & DRN & $\mathrm{km} / \mathrm{km}^{2}$ \\
\hline & \multirow{2}{*}{$\begin{array}{l}\text { Public service development } \\
\text { (PSD) }\end{array}$} & $\begin{array}{l}\text { Number of primary and secondary schools per } \\
\qquad 1,000 \text { people }(+)(x 4)\end{array}$ & NPSSP & Number \\
\hline & & Number of medical beds per 1,000 people $(+)(x 5)$ & NMBP & Number \\
\hline \multirow{11}{*}{$\begin{array}{l}\text { Tourism development } \\
\text { TD }(y)\end{array}$} & \multirow{3}{*}{$\begin{array}{l}\text { Tourism economic } \\
\text { environment (TEE) }\end{array}$} & Per capita GDP $(+)(y 1)$ & PGDP & yuan \\
\hline & & $\begin{array}{l}\text { Growth rate of tertiary industry output value }(+) \\
(y 2)\end{array}$ & GRTIOV & $\%$ \\
\hline & & $\begin{array}{l}\text { Ratio of tertiary industry output value to GDP }(+) \\
\qquad(y 3)\end{array}$ & RTIOVGDP & $\%$ \\
\hline & \multirow{3}{*}{ Tourism social benefit (TSB) } & Tourism consumption per capita $(+)(y 4)$ & TCC & yuan \\
\hline & & $\begin{array}{l}\text { Ratio of tourists to tertiary industry employees } \\
\qquad(+)(y 5)\end{array}$ & RTTIE & $\%$ \\
\hline & & Number of staffs in danwei $(+)(y 6)$ & NSWD & 10,000 people \\
\hline & \multirow[b]{2}{*}{$\begin{array}{l}\text { Tourism economic benefit } \\
\text { (TEB) }\end{array}$} & Contribution of tourism revenue to GDP $(+)(y 7)$ & CTRGDP & $\%$ \\
\hline & & $\begin{array}{l}\text { Ratio of tourism revenue to tertiary industry }(+) \\
(y 8)\end{array}$ & RTRTI & $\%$ \\
\hline & \multirow{3}{*}{$\begin{array}{c}\text { Tourism development vitality } \\
\text { (TDV) }\end{array}$} & Retail sales of hoteling and catering trade $(+)(y 9)$ & RSHCT & 100 million $¥$ \\
\hline & & Growth rate of tourists $(+)(y 10)$ & GRT & $\%$ \\
\hline & & Growth rate of tourism revenue $(+)(y 11)$ & GRTR & $\%$ \\
\hline
\end{tabular}

TABLE 2: Evaluation grade of $T$ of AT and TD.

\begin{tabular}{lllll}
\hline Value & $T<0.25$ & $0.25<T<0.50$ & $0.50<T<0.75$ & $T \geq 0.75$ \\
\hline Grade & Poor & Fair & Good & Excellent \\
\hline
\end{tabular}

$$
C=\frac{1}{m \times l} \sum_{i=1}^{m} \sum_{j=1}^{l} \xi_{i j}
$$

the relationship of subsystems that work together harmoniously [63].

(1) Calculating the coupling degree $(C)$ of AT and TD. A gray correlation method was employed [5]: where $\quad \xi_{i j}=\min _{i} \min _{j}\left|X_{i}^{\prime}-Y_{j}^{\prime}\right|+\rho \max \max \left|X_{i}^{\prime}-Y_{j}^{\prime}\right| /$ $\left|X_{i}^{\prime}-Y_{j}^{\prime}\right|+\rho \max \max _{j}^{j}\left|X_{i}^{\prime}-Y_{j}^{\prime}\right|$, which represents the gray relational coefficient; $m=5$ and $l=11$ are the numbers of variables of AT and TD, respectively. $C$ is 
the coupling degree $(0 \leq C \leq 1)$, which was divided into four levels [64] (Table 3). When $C=0$, AT and TD are irrelevant. When $0 \leq C \leq 0.3$, there is a low-coupling phase with low-level TD demand and high-level AT supply. When $0.3 \leq C \leq 0.5$, AT and TD are in the antagonistic stage, and the increase in TD demand causes disorder in the AT with a decline in AT supply. When $0.5 \leq C \leq 0.8$, AT and TD are in a running-in phase, in which the TD enhances AT, and AT, in turn, upgrades tourism facilities to further promote development. When $0.8 \leq C<1$, there is a high-level coupling phase in which AT and TD achieve harmony benefit. If $C=1$, a benign resonance coupling phase is achieved, and AT and TD progress toward a new ordered structure with optimal TD and balanced AT supply and demand.

(2) Calculating the coupling coordination degree $(D)$ of $\mathrm{AT}$ and TD.

The coupling degree does not fully reflect the comprehensive development level of AT and TD. Therefore, the coupling coordination degree $(D)$ was employed [64]. The formula is as follows:

$$
D=\sqrt{C \times T} .
$$

Studies have indicated that $D$ is divided into 3 classes, 6 subclasses, and 18 types $[17,41]$ (Table 4 ).

3.3.3. Calculating the Influencing Factors of $C$ and $D$. For cross-sectional data of 74 prefectural units of Tibet in 2015, a multiple linear regression model was used to identify the influencing factors of spatial differences of $C$ and $D$ $[65,66]$ :

$$
\begin{aligned}
y= & c+\alpha_{1} \times \mathrm{AT}_{1}+, \cdots, \alpha_{5} \times \mathrm{AT}_{5}+\beta_{1} \times \mathrm{TD}_{1}, \cdots, \\
& +\beta_{11} \times \mathrm{TD}_{11}+\varepsilon,
\end{aligned}
$$

where $y$ is $C$ or $D ; \alpha$ and $\beta$ are the coefficients; $\mathrm{AT}_{1} \ldots \mathrm{AT}_{5}$ are variables of $\mathrm{AT}(x) ; \mathrm{TD}_{1} \ldots \mathrm{TD}_{5}$ are variables of $\mathrm{TD}(y)$; and $\varepsilon$ is the residual.

\section{Results and Discussion}

4.1. The Comprehensive Development Degree (T) of ATand TD. In the time series, $T$ increased to the "excellent" grade (0.802 in 2015) from the "poor" grade (0.168 in 1991). AT ( $x$ ) and TD $(y)$ achieved the "good" (0.711 in 2015) and "excellent" grades (0.847 in 2015), respectively (Figure 2). T, AT (x), and TD $(y)$ declined in 1996 and then increased in 1997.

Before 1996, AT $(x)$ was larger than TD $(y)$; however, TD $(y)$ surpassed AT $(x)$ after 1996. Correspondingly, the relative development degree was $\eta>1.20$ from 1991 to 1996, $0.80 \eta<1.20$ from 1997 to 2008 , and $0 \eta<0.80$ from 2009 to 2015. These results indicated that AT and TD changed from TD-lagged to AT-lagged and then to AT and TD synchronized (Figure 2).
The spatial distribution minimum, maximum, mean, median, and standard deviation of AT $(x)$ in 2015 were $0.055,0.600,0.269,0.268$, and 0.096 , respectively. The areas with larger AT $(x)$ than the mean were distributed in marginal Tibet, whereas areas with smaller AT $(x)$ than the mean were mainly concentrated in central Tibet (Figure 3(a)).

The minimum, maximum, mean, median, and standard deviation of TD $(y)$ in 2015 were $0.126,0.521,0.231,0.203$, and 0.083 , respectively. The areas with higher TD $(y)$ than the mean were distributed in marginal Tibet, whereas the areas with smaller TD $(y)$ than the mean were distributed in central Tibet (Figure 3(b)).

AT $(x)$ and TD $(y)$ displayed a "core-periphery" spatial pattern, and both are lower in the center.

Because both AT $(x)$ and TD $(y)$ are relatively low in central regions and high in marginal regions, $T$ is also low in central and high in marginal Tibet (Figure 3(c)). Compared with $\operatorname{TD}(y), \operatorname{AT}(x)$ is smaller in central regions and larger in marginal ones. Therefore, $\eta$ is low in central Tibet and high in marginal Tibet (Figure 3(d)).

4.2. Results of Coupling Coordination Degree of AT and TD. In terms of time series, from 1991 to 2015, $C$ was always in the "running-in phase," whereas $D$ increased to the "favorably balanced development" (FBD, 0.754 in 2015) from the "moderately unbalanced development" (MUD, 0.343 in 1991) (Figure 4). These results indicated that the coupling interactions of AT and TD were strong, and the coordinated development of AT and TD improved substantially.

The spatial pattern minimum, maximum, mean, median, and standard deviation values of $C$ in 2015 were $0.590,0.773$, $0.661,0.653$, and 0.035 , respectively. The coupling level was generally high (running-in phase) across the 74 units. The areas with larger values of $C$ than the mean were distributed in central Tibet, whereas areas with smaller values of $C$ than the mean were distributed in marginal Tibet (Figure 5(a)).

The minimum, maximum, mean, median, and standard deviation values of $D$ in 2015 were $0.285,0.548,0.397,0.383$, and 0.054 , respectively. The coordination level was relatively low (MUD) across the 74 units. Areas with larger values of $D$ than the mean were concentrated in marginal Tibet, whereas areas with smaller values of $D$ than the mean were distributed in central Tibet (Figure 5(b)).

The coupling coordination level was classified into the MUD, SUD, and BBD (Figure 5(c)). The MUD (0.285-0.400) had 45 units, which were mainly concentrated in the Qamdo, "Yijiangsihe" region, and Ngari Prefecture. The SUD (0.401-0.500) had 25 units, which were mainly concentrated in Nyingchi-Lhoka region, Nagqu-Shigatse region, and western Ngari Prefecture. The BBD (0.501-0.548) had four units, which are the capitals of Lhasa Prefecture, Nyingchi Prefecture, and Ngari Prefecture.

Both $C$ and $D$ display a "core-periphery" spatial pattern. However, $C$ was higher in the center and $D$ was higher in the periphery.

Central Tibet displayed relatively bigger external effects from the assistance which caused small differentiations in 
TABLE 3: Evaluation grade of the $C$ of AT and TD.

\begin{tabular}{lcccc}
\hline Value & $0<C \leq 0.30$ & $0.30<C \leq 0.50$ & $0.50<C \leq 0.80$ & $0.80<C<1.00$ \\
\hline Coupling level & Low-coupling phase & Antagonistic stage & Running-in phase & High-level coupling phase \\
\hline
\end{tabular}

TABLE 4: Coordinated development types of AT and TD.

\begin{tabular}{ll}
\hline Classes & Subclasses \\
\hline & \\
& $0.0<D \leq 0.2 \quad \begin{array}{l}\text { Seriously unbalanced } \\
\text { development (SeUD) }\end{array}$
\end{tabular}

Unbalanced

development

\begin{tabular}{|c|c|c|}
\hline ypes & & \\
\hline $\begin{array}{l}(x)<\mathrm{TD} \\
(y)\end{array}$ & I-A & $\begin{array}{l}\text { Seriously unbalanced } \\
\text { hinc }\end{array}$ \\
\hline $\begin{array}{c}\mathrm{AT}(x)=\mathrm{TD} \\
(y)\end{array}$ & I-B & $\begin{array}{l}\text { Seriously unbalance } \\
\text { and TD s }\end{array}$ \\
\hline $\begin{array}{c}\operatorname{AT}(x)>\mathrm{TD} \\
(y)\end{array}$ & $\mathrm{I}-\mathrm{C}$ & $\begin{array}{r}\text { Seriously unbalanced } \\
\text { hin }\end{array}$ \\
\hline $\begin{array}{c}\mathrm{AT}(x)<\mathrm{TD} \\
(y)\end{array}$ & II-A & $\begin{array}{r}\text { Moderately unbalanc } \\
\text { hir }\end{array}$ \\
\hline $\begin{array}{c}\mathrm{AT}(x)=\mathrm{TD} \\
(y)\end{array}$ & II-B & $\begin{array}{r}\text { Moderately unbalan } \\
\text { and TD }\end{array}$ \\
\hline $\begin{array}{c}\mathrm{AT}(x)>\mathrm{TD} \\
(y)\end{array}$ & $\mathrm{I}-\mathrm{C}$ & $\begin{array}{r}\text { Moderately unbala } \\
\text { TD }\end{array}$ \\
\hline $\mathrm{AT}(x)<\mathrm{TD}$ & A & AT- \\
\hline $\mathrm{AT}(x)=\mathrm{TD}$ & III- & \\
\hline $\begin{array}{l}(x)>\mathrm{TD} \\
(y)\end{array}$ & III- & TD- \\
\hline $\begin{array}{c}\mathrm{AT}(x)<\mathrm{TD} \\
(y)\end{array}$ & $\begin{array}{c}\text { IV- } \\
\text { A }\end{array}$ & Bare \\
\hline $\begin{array}{r}\mathrm{AT}(x)= \\
(y)\end{array}$ & $\begin{array}{c}\text { IV- } \\
\text { B }\end{array}$ & sy \\
\hline $\begin{array}{c}\mathrm{AT}(x)>\mathrm{TD} \\
(y)\end{array}$ & $\begin{array}{c}\text { IV- } \\
\text { C }\end{array}$ & Barely \\
\hline $\begin{array}{c}\mathrm{AT}(x)<\mathrm{TD} \\
(y)\end{array}$ & V-A & la \\
\hline $\begin{array}{c}\mathrm{AT}(x)=\mathrm{TD} \\
(y)\end{array}$ & $\mathrm{V}-\mathrm{B}$ & $\begin{array}{r}\text { Favorably balanced de } \\
\text { TD syn }\end{array}$ \\
\hline $\mathrm{AT}(x)>\mathrm{TD}$ & $\mathrm{V}-\mathrm{C}$ & $\begin{array}{r}\text { Favorably balanced d } \\
\text { lag }\end{array}$ \\
\hline $\begin{array}{c}\mathrm{AT}(x)<\mathrm{TD} \\
(y)\end{array}$ & $\begin{array}{l}\text { VI- } \\
\text { A }\end{array}$ & Superiorly balanced \\
\hline $\mathrm{AT}(x)=\mathrm{TD}$ & $\begin{array}{l}\text { VI- } \\
\text { B }\end{array}$ & $\begin{array}{l}\text { Superiorly balanced development with AT and } \\
\text { TD synchronized }\end{array}$ \\
\hline $\begin{array}{c}\mathrm{AT}(x)>\mathrm{TD} \\
(y)\end{array}$ & $\begin{array}{l}\text { VI- } \\
\text { C }\end{array}$ & $\begin{array}{c}\text { Superiorly balanced development with TD- } \\
\text { lagged }\end{array}$ \\
\hline
\end{tabular}

Balanced

development

Moderately unbalanced

$0.2<D \leq 0.4$ development (MUD)

Transitional

development

Slightly unbalanced development (SUD)
$0.5<D \leq 0.6 \quad$ Barely balanced development (BBD)
$0.8<D \leq 1$
Superiorly balanced development (SBD)
Favorably balanced development (FBD) lagged

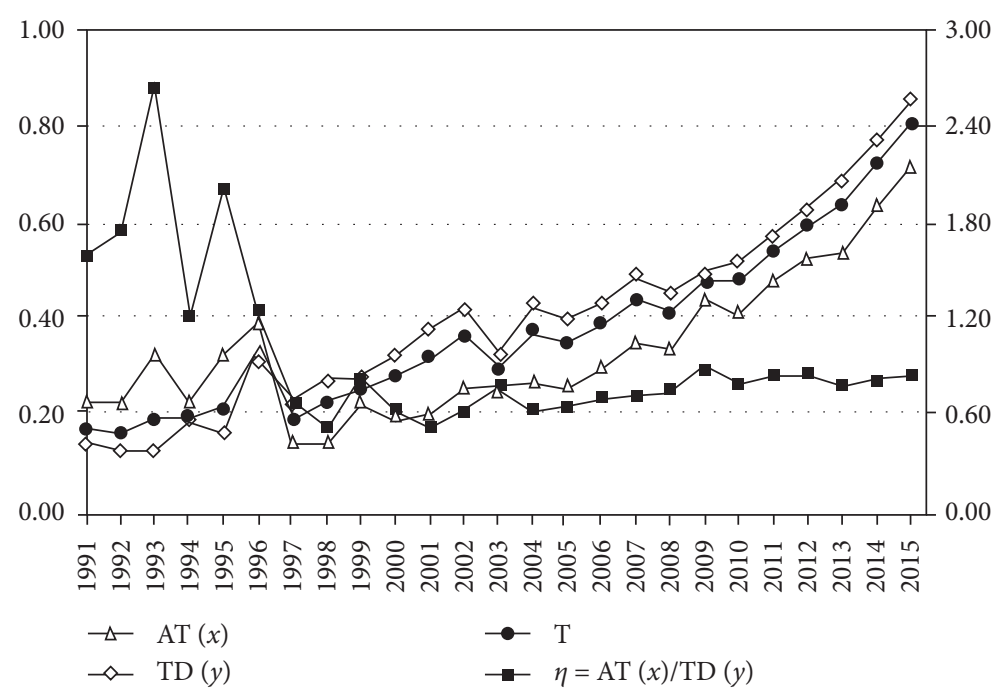

Figure 2: Changes of AT $(x)$, TD $(y), T$, and $\eta$ from 1991 to 2015. 


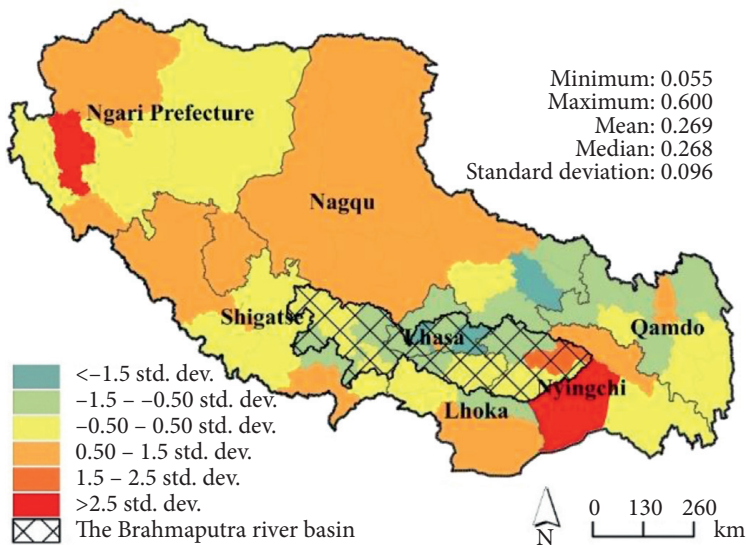

(a)

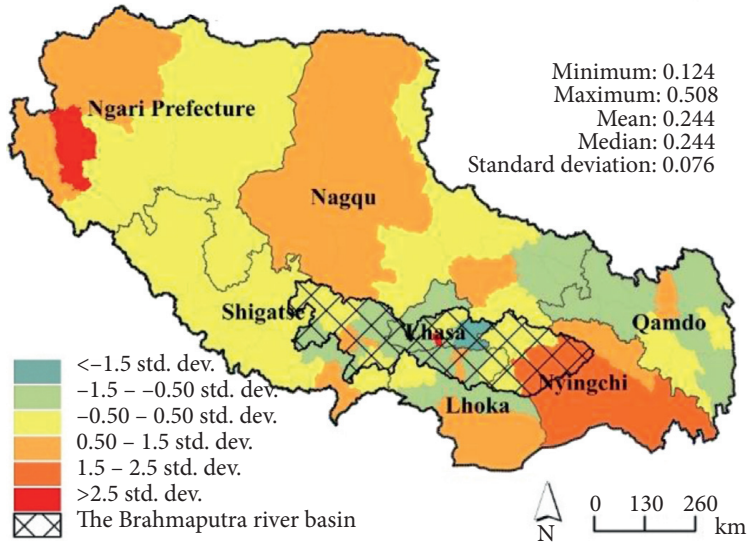

(c)

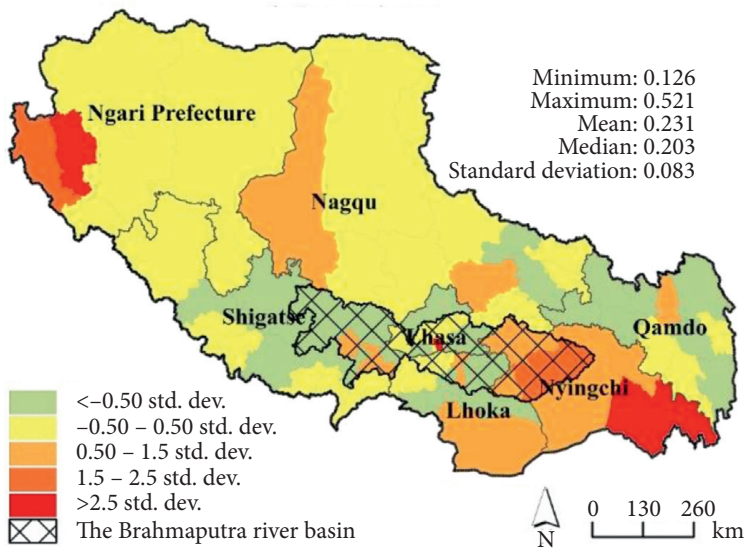

(b)

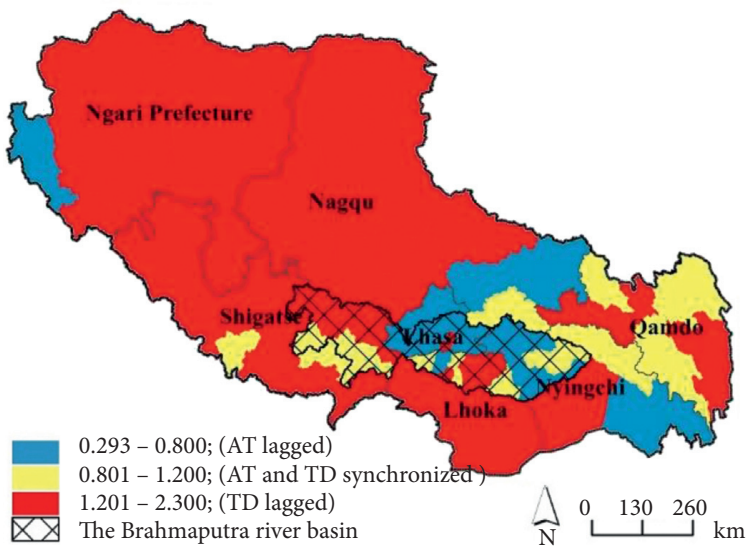

(d)

FIgURE 3: The spatial pattern of AT $(x)$, TD $(y), T$, and $\eta$ in 2015. (a) Integration value of AT (b) Integration value of TD (c) Comprehensive development of degree (T) of AT and TD (d) Relative development degree $(\eta)$ of AT and TD.

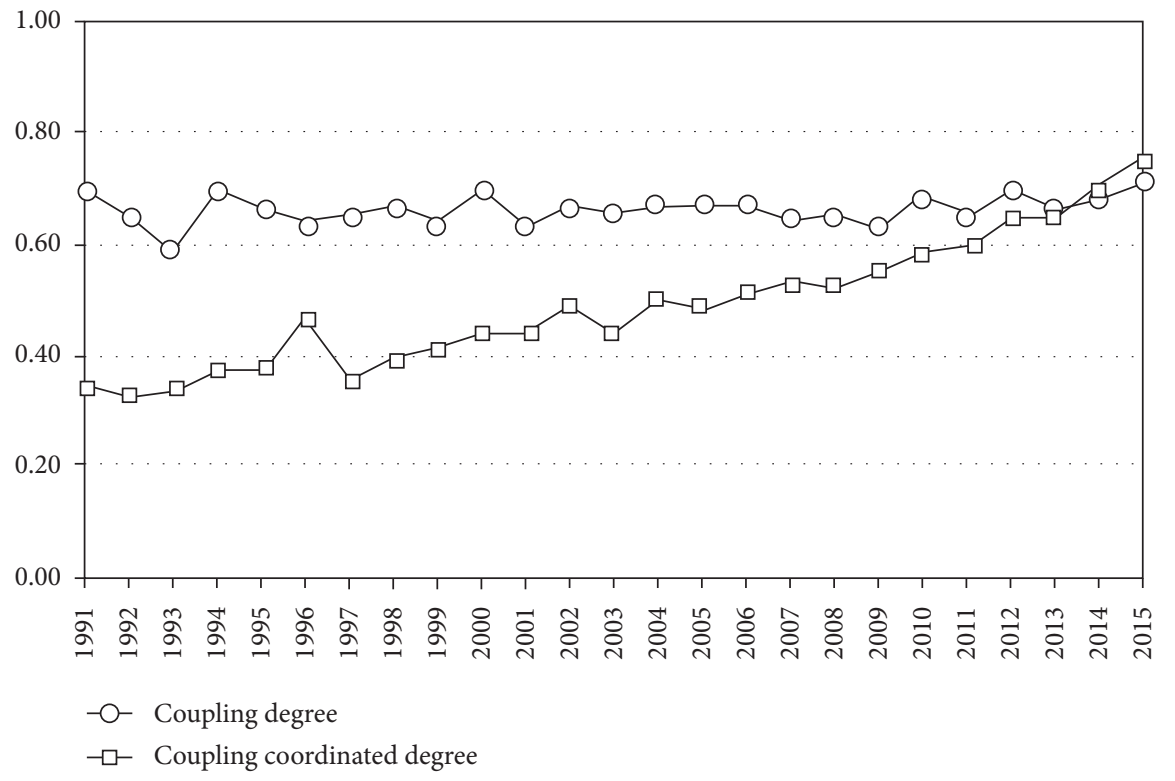

FIgURE 4: Time-series changes of coupling degree and coupling coordination degree of AT and TD (1991-2015). 


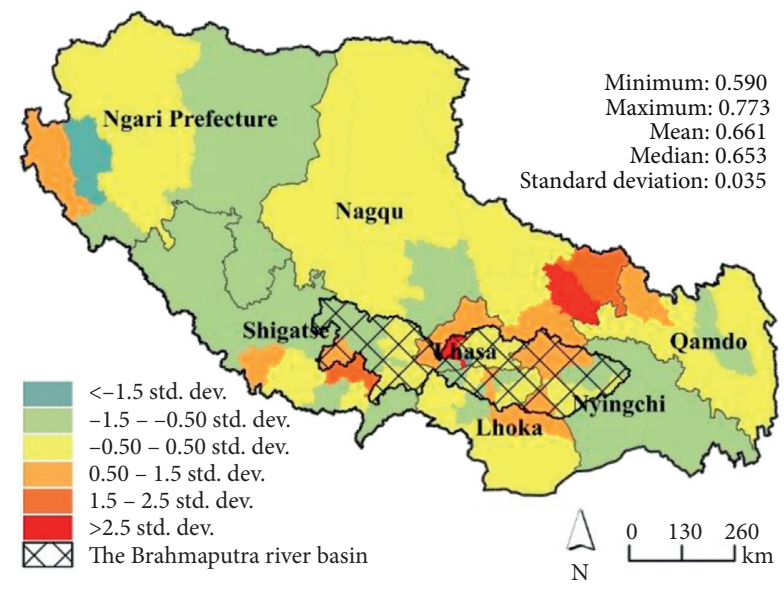

(a)

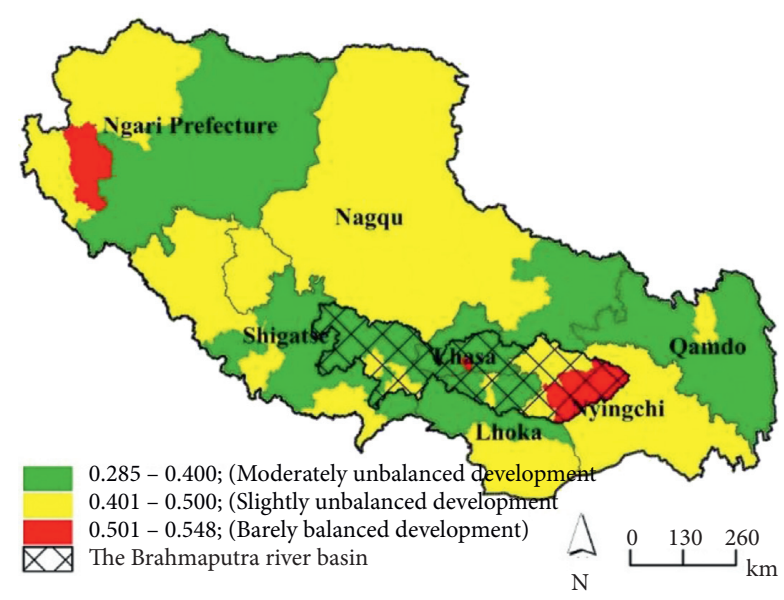

(c)

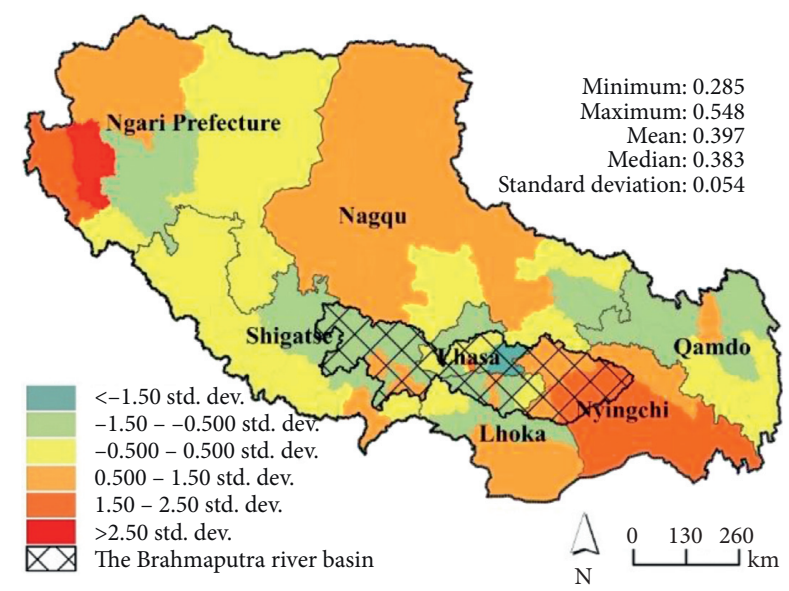

(b)

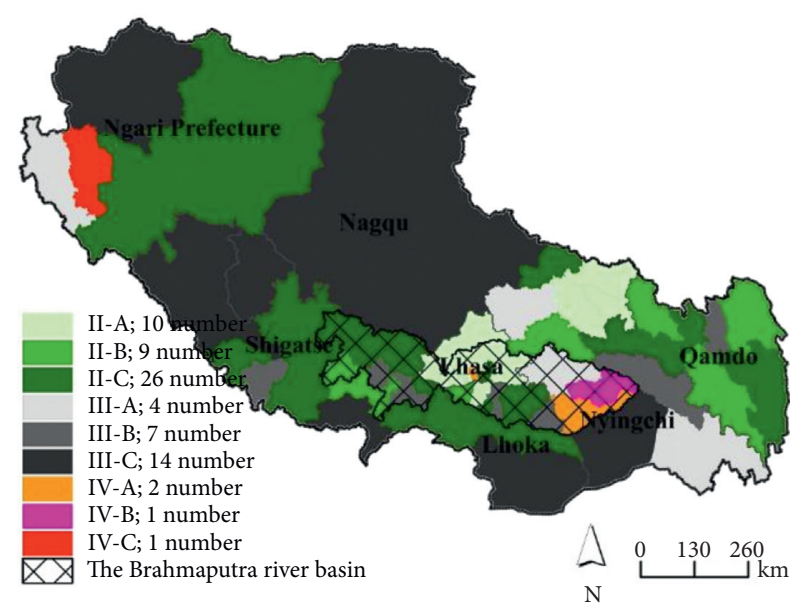

(d)

Figure 5: Spatial distribution of $C$ and $D$, coupling coordination level, and coordinated development types of AT and TD in 2015. (a) Coupling degree $(C)$. (b) Coupling coordination degree $(D)$. (c) Coupling coordination level. (d) Coupling development types.

socioeconomic development, which led to a higher coupling relationship between AT and TD. However, central Tibet is low-lying ground of assistance, and the AT $(x)$, TD $(y)$, and $D$ were relatively low.

Marginal Tibet obtained small external effects from assistance, which led to a lower coupling relationship between AT and TD. However, marginal Tibet was in the highlands of assistance, and the AT $(x)$, TD $(y)$, and $D$ were relatively high.

Therefore, differentiated strategies should be adopted to improve the coordinated development level of AT and TD.

4.3. Types of Coordinated Development of AT and TD. As illustrated in Table 4, coordinated development types were identified (Figure 5(d)).

Type II-A (10 units) is the MUD with AT-hindered type, which is characterized by a relatively small $T\left(\bar{T}_{\text {II-A }}=0.178\right)$ and an $\operatorname{AT}(x)$ that is smaller than TD $(y)$. This type is mainly concentrated in Lhasa and eastern Nagqu (i.e., Biru-SuoxianBaqing region). Type II-B (9 units) is the MUD with AT and TD synchronized type, which is characterized by a relatively small $T$
$\left(\bar{T}_{\mathrm{II}-\mathrm{B}}=0.191\right)$ and an AT $(x)$ that is approximately equal to TD (y). This type is scattered in Qamdo, Nagqu, Lhoka, and Shigatse. Type II-C (26 units) is the MUD with TD-hindered type, which is characterized by a relatively small $T\left(\bar{T}_{\text {II-C }}=0.204\right)$ and an AT $(x)$ that is larger than TD $(y)$. This type is concentrated in the western Ngari Prefecture (i.e., Gaize-Geji-Pulan region) and the Shigatse-Lhoka region and scattered in Qamdo.

Type III-A (4 units) is the SUD with AT-hindered type, which is characterized by a median $T\left(\bar{T}_{\text {III-A }}=0.333\right)$ and an AT $(x)$ that is larger than TD $(y)$. This type is scattered in the units of Nyingchi, Nagqu, and Ngari Prefecture. Type III-B (7 units) is the SUD with AT and TD synchronized type, which is characterized by a median $T\left(\bar{T}_{\text {III-B }}=0.297\right)$ and an AT $(x)$ that is approximately equal to TD $(y)$. This type is scattered in Qamdo, Nagqu, Lhoka, and Shigatse. Type III-C (14 units) is the SUD with TD-hindered type, which is characterized by median $T$ $\left(\bar{T}_{\text {III-C }}=0.288\right)$ and an AT $(x)$ that is larger than TD $(y)$. This type is mainly located in the western Ngari Prefecture, NagquShigatse region, southern Shigatse, and Nyingchi-Lhoka region.

Type -A (2 units) is the BBD with AT-lagged type, which is characterized by a relatively high $T\left(\bar{T}_{\text {IV-A }}=0.430\right)$ and an AT $(x)$ that is larger than TD $(y)$. This type is located in Milin 


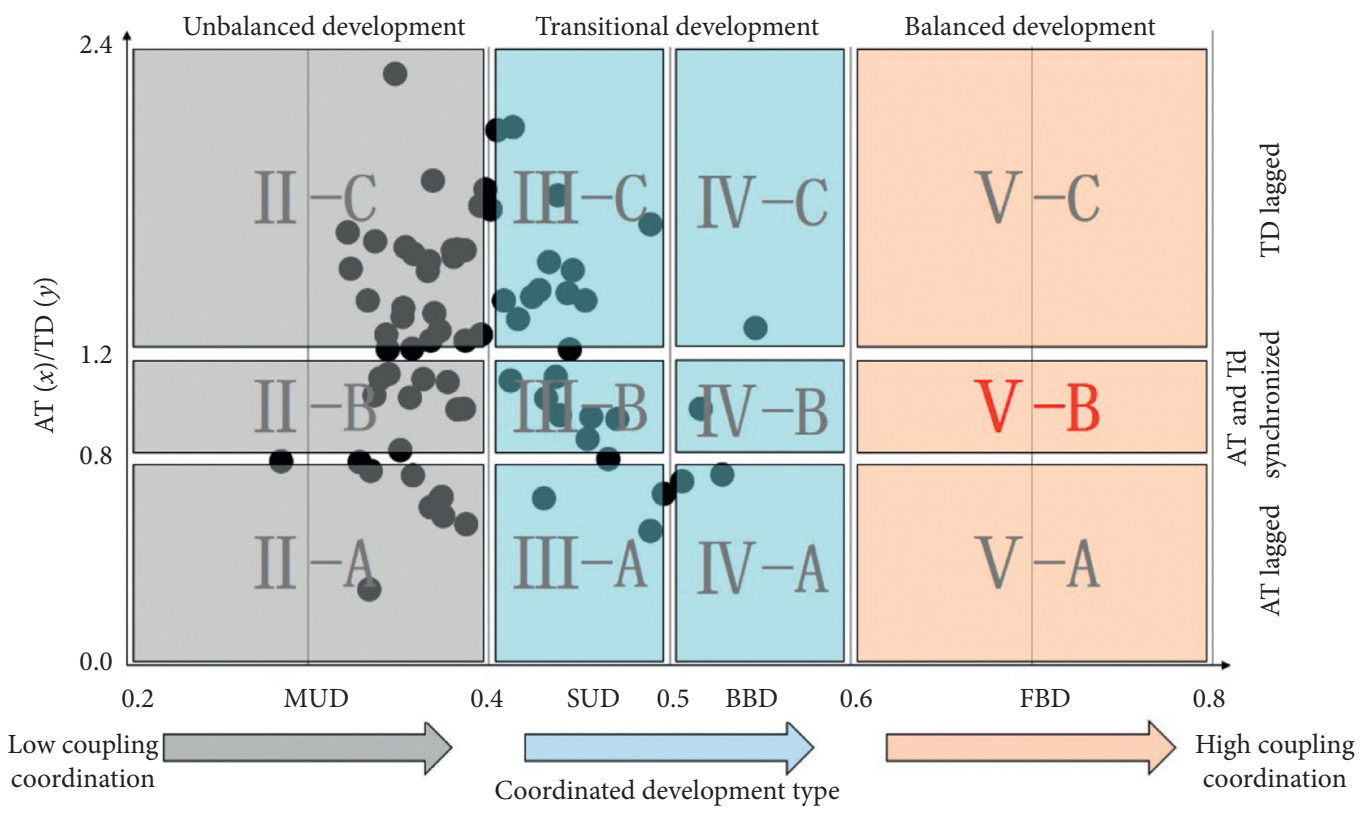

FIGURE 6: Evolution of the coordinated development types of ATTD. Note: $\bar{T}_{\text {II-A }}=0.178, \bar{T}_{\text {II-B }}=0.191, \bar{T}_{\text {II-C }}=0.204 ; \bar{T}_{\text {III-A }}=0.333$, $\bar{T}_{\text {III-B }}=0.297, \bar{T}_{\text {III-C }}=0.288 ; \bar{T}_{\text {IV-A }}=0.430, \bar{T}_{\text {IV-B }}=0.430$, and $\bar{T}_{\text {IV-C }}=0.508$.

TABLE 5: Results of OLS method of the MLR model.

\begin{tabular}{|c|c|c|c|c|c|c|}
\hline \multirow{2}{*}{ Variables } & \multicolumn{3}{|c|}{$C$} & \multicolumn{3}{|c|}{$D$} \\
\hline & Coefficient & Std. error & $T$ statistic & Coefficient & Std. error & $T$ statistic \\
\hline Constant & 0.679 & 0.019 & $34.878^{* * *}$ & 0.199 & 0.006 & $33.487^{* * *}$ \\
\hline X1_FTP & -0.039 & 0.036 & -1.093 & 0.004 & 0.011 & 0.401 \\
\hline X2_RIIFAI & -0.079 & 0.017 & $-4.578^{* * *}$ & 0.026 & 0.005 & $4.910^{* * *}$ \\
\hline X3_DRN & -0.032 & 0.026 & -1.247 & 0.027 & 0.008 & $3.396^{* * *}$ \\
\hline X4_NPSSP & -0.078 & 0.017 & $-4.498^{* * *}$ & 0.068 & 0.005 & $12.750^{* * *}$ \\
\hline X5_NMBP & -0.041 & 0.038 & -1.092 & 0.041 & 0.012 & $3.575^{* * *}$ \\
\hline Y1_PGDP & -0.014 & 0.035 & -0.405 & 0.051 & 0.011 & $4.683^{* * *}$ \\
\hline Y2_GRTIOV & -0.011 & 0.029 & -0.370 & 0.034 & 0.009 & $3.808^{* * *}$ \\
\hline Y3_RTIOVGDP & 0.047 & 0.016 & $2.922^{* * *}$ & 0.109 & 0.005 & $22.240^{* * *}$ \\
\hline Y4_TCC & 0.010 & 0.023 & 0.459 & 0.083 & 0.007 & $11.890^{* * *}$ \\
\hline Y5_RTTIE & 0.008 & 0.016 & 0.523 & 0.027 & 0.005 & $5.359^{* * *}$ \\
\hline Y6_NSWD & 0.039 & 0.076 & 0.510 & 0.011 & 0.023 & 0.483 \\
\hline Y7_CTRGDP & 0.131 & 0.033 & $4.006^{* * *}$ & 0.122 & 0.010 & $12.231^{* * *}$ \\
\hline Y8_RTRTI & -0.037 & 0.040 & -0.933 & -0.007 & 0.012 & -0.601 \\
\hline Y9_RSHCT & -0.102 & 0.076 & -1.331 & 0.033 & 0.023 & 1.409 \\
\hline Y10_GRT & -0.042 & 0.063 & -0.668 & 0.025 & 0.019 & 1.314 \\
\hline Y11_GRTR & -0.033 & 0.086 & -0.384 & 0.031 & 0.026 & 1.192 \\
\hline $\mathrm{R} 2$ & 0.676 & & & 0.987 & & \\
\hline Adj. R2 & 0.585 & & & 0.984 & & \\
\hline S.E. of regression & 0.023 & & & 0.007 & & \\
\hline$F$ statistic & 7.434 & & & 277.035 & & \\
\hline Obs $* \mathrm{R} 2$ & 0.849 & & & 0.614 & & \\
\hline
\end{tabular}

Note: “***” represents significant at $1 \%$ level.

County and in Chengguan District, the capital of Lhasa. Type IV-B (1 unit) is the BBD with AT and TD synchronized type, which is characterized by a relatively high $T\left(\bar{T}_{\mathrm{IV}-\mathrm{B}}=0.430\right)$ and an $\operatorname{AT}(x)$ that is approximately equal to TD $(y)$. This type is concentrated in Bayi District, the capital of Nyingchi. Type IV-C (1 unit) is the BBD with TD-lagged type, which is characterized by a relatively high $T\left(\bar{T}_{\mathrm{IV}-\mathrm{C}}=0.508\right)$ and an AT $(x)$ that is smaller than TD $(y)$. This type is located in Gaer County, the capital of Ngari Prefecture.
Increasing $\mathrm{AT}(x)$ and TD $(y)$ and balancing them to higher coordination levels is generally a challenge (V-B) (Figure 6).

4.4. Influencing Factors of the Spatial Differentiation of $C$ and $D$. By employing the multicollinearity test and heteroscedasticity test, we estimate the MLR model. The results are presented in Table 5.

For the spatial differentiation of $C$, the OLS method indicated that the RIIFAI and NPSSP (AT factors) had 


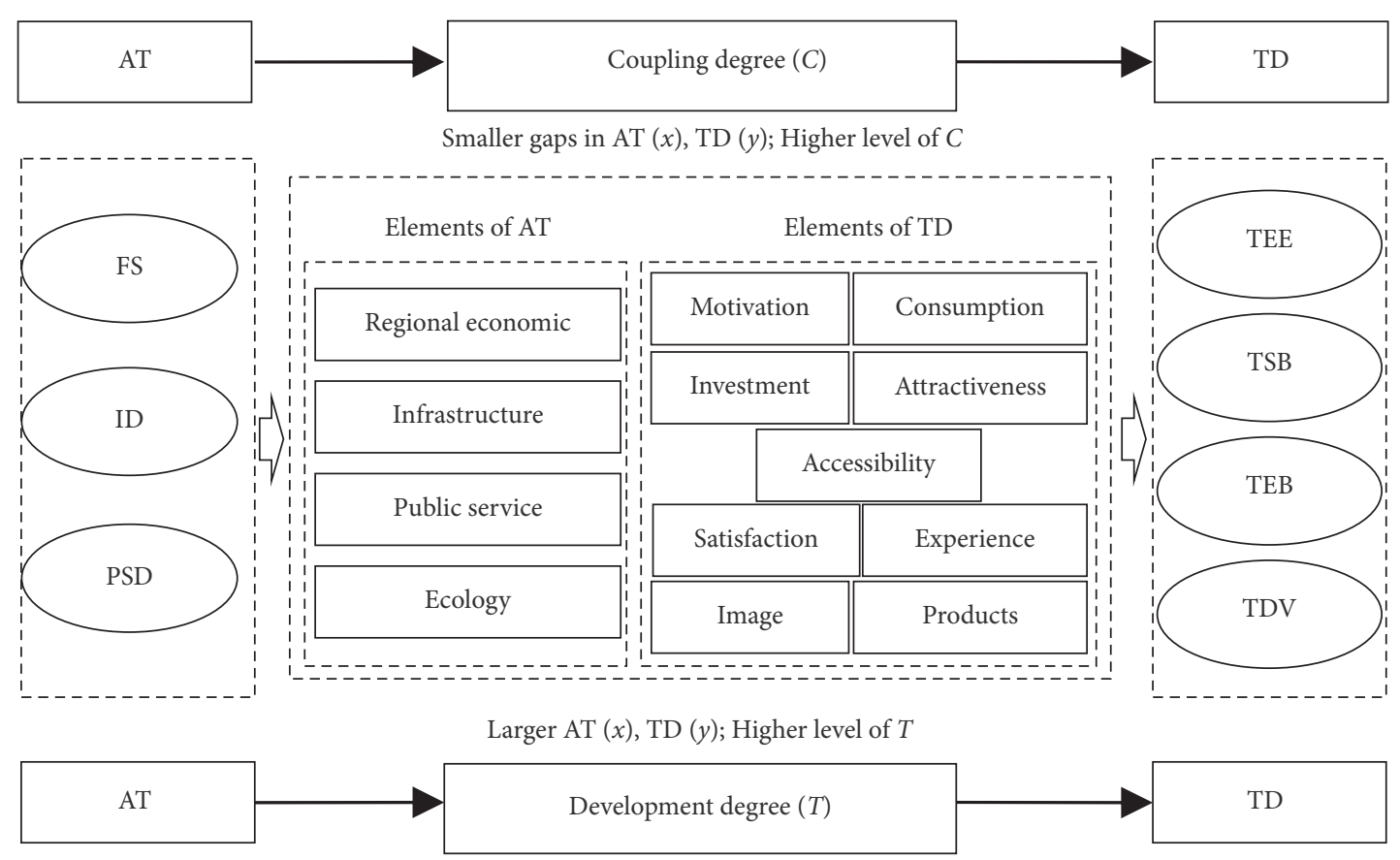

Figure 7: Dynamics of the coordinated development of AT and TD.

significant positive effects at a $1 \%$ significant level, whereas RTIOVGDP and CTRGDP (TD factors) had significant negative effects.

For the spatial differentiation of $D$, the OLS method indicated that both AT and TD displayed significant effects. The RIIFAI, DRN, NPSSP, and NMBP AT factors had significant positive effects at a significance level of $1 \%$, whereas the effects of FTP were not significant at the $1 \%$ level; the PGDP, GRTIOV, RTIOVGDP, TCC, RTTIE, and CTRGDP TD factors had significant positive effects at a $1 \%$ significance level, whereas the effects of NSWD, RTRTI, RSHCT, GRT, and GRTR are not significant at 1\% level.

These results indicate that AT factors of ID and PD have significant effects on the spatial differentiation of $D$, whereas the effects of FA were not significant. The TD factors of TEE, TSB, and TEB had significant effects on the spatial differentiation of $D$, whereas the effects of TDV were not significant.

The results indicated that the improvement of socioeconomic conditions and tourism facilities promoted tourism in Tibet. These improvements were rooted in the financial assistance, infrastructure construction, and public service investments.

The assistance established a basic framework for socioeconomic development in Tibet, which provided the socioeconomic conditions for tourism, such as economic, infrastructural, service, and environmental improvements.

However, the socioeconomic conditions forced Tibet tourism to promote its image, products, attractiveness, and accessibility to enhance tourism, which aggrandized the tourism scale, quality, and benefits, both directly and indirectly. For instance, tourist, employee, tourism revenue, and tourism-related industries developed.
Assistance increased and tourism improved, which promoted AT $(x)$ and TD $(y)$. If AT $(x)$ and TD $(y)$ improve, then $T$ flourishes; otherwise, it declines. If differences between $\operatorname{AT}(x)$ and TD $(y)$ decrease, then $C$ increases; otherwise, it decreases. The coordinated development of AT and TD was the unification of $C$ and $T$ (Figure 7 ).

\section{Conclusions}

The analysis of spatiotemporal dynamics and influencing factors of coordinated development of AT and TD led to the following conclusions:

(1) AT had strong, continuous coupling interactions with TD. The coordination degree increased (BBD) under this interaction. However, the level remained relatively low (MUD) across Tibet.

(2) The lower-level coordinated development types were predominant in central Tibet, whereas the higherlevel ones were predominant in marginal Tibet. The spatial pattern highly coincides with the patterns of AT $(x)$ and TD $(y)$ (i.e., low in center and high in the periphery).

(3) AT and TD factors had significant positive effects on the spatial pattern of the degree of coupling coordination, but not on the spatial pattern of the coupling degree, especially the ID, PSD, TEE, TSB, and TEB.

To improve the coordinated development level in central and marginal Tibet, the following suggestions are provided.

(1) Further intensifying the AT. The analysis indicated that AT has high coupling interactions with TD, but the 
degree of coordination remains low for most units in Tibet. Therefore, assistance should be further increased to improve tourism in Tibet. (2) Adopting policies that suit local idiosyncrasies. The analysis demonstrated that the coupling coordination degree was low in the center and high in the periphery. Therefore, the focus for central and marginal Tibet should be improving the comprehensive development level $(T)$ and coupling degree $(C)$, respectively. (3) Ensuring the accuracy of the AT. The analysis indicated that ID and PSD could effectively promote the coordination of AT and TD. Furthermore, AT $(x)$ and TD $(y)$ are low in center and high in the periphery.

The limitation of this study was the difficulty of obtaining the most recent data from 74 prefectural units of the Tibet Autonomous Region, which may have caused an underestimation of the coordinated development level of AT and TD in the current period. However, our empirical results are beneficial for understanding the coordinated development of AT and TD and can thus help improve AT $(x), \mathrm{TD}(y)$, and narrow regional differences.

\section{Data Availability}

The data used in this study are available from the first author upon request.

\section{Conflicts of Interest}

The authors declare no conflicts of interest.

\section{Acknowledgments}

This work was supported by the National Social Science Foundation of China (grant number 17BRK010).

\section{References}

[1] D. D. Lu, Y. Liu, and J. Fan, "The regional policy effects and regional development states in China (in Chinese)," Acta Geographica Sinica, vol. 54, no. 6, pp. 496-508, 1999.

[2] C. S. Zhou, W. J. Xie, and J. L. Wu, "Review and prospect of regional planning practices and theories in China since the reform and opening up (in Chinese)," Areal Research and Development, vol. 36, no. 1, pp. 1-6, 2017.

[3] L. Guo, "Evolution of China's regional economy development strategy after the founding of the PRC-also on logical evolution of regional equity and efficiency goals (in Chinese)," Taxation And Economy, vol. 6, pp. 18-23, 2009.

[4] M. Fujita and D. Hu, "Regional disparity in China 1985-1994: the effects of globalization and economic liberalization," The Annals of Regional Science, vol. 35, no. 1, pp. 3-37, 2001.

[5] C. S. Zhou, B. Yu, C. Y. Shi, and Y. Q. Wang, "The coupling and coordinating analysis between aiding Tibet and economic development in Tibet Autonomous Region (in Chinese)," Scientia Geographica Sinica, vol. 38, no. 2, pp. 206-213, 2018.

[6] M. H. Yang and L. You, "Study osn resources reallocation of partner assisstance to Tibet and its optimization pattern (in Chinese)," Reform Of Economic System, vol. 4, pp. 62-69, 2018, s.

[7] X. J. Li and J. J. Qiao, "County level economic disparities of China in the 1990s (in Chinese)," Acta Geographica Sinica, vol. 56, no. 2, pp. 136-145, 2001.
[8] Y. Liu, "Central government's supportive policy on Tibet and national aids to it (in Chinese)," Western China Development Review, vol. 5, no. 3, pp. 42-50, 2005.

[9] L. Wang and Y. S. Huang, "Research on the approach to promoting the effectiveness of hand-in-hand aid in Tibet: a perspective based on the demand of farmers and herdsmen (in Chinese)," Guizhou Ethnic Studies, vol. 35, no. 8, pp. 163-166, 2015.

[10] X. L. Tian and Z. J. Yu, "Aiding for tourism in Xizang and Xizang tourism destination development research (in Chinese)," Resource Development \& Market, vol. 31, no. 2, pp. 249-252, 2015.

[11] J. C. Huang and C. L. Fang, "Analysis of coupling mechanism and rules between urbanization and eco-environment (in Chinese)," Geographical Research, vol. 22, no. 2, pp. 211-220, 2003.

[12] Y.-B. Liu, R.-D. Li, and C.-H. Li, "Scenarios simulation of coupling system between urbanization and eco-environment in Jiangsu province based on system dynamics model," Chinese Geographical Science, vol. 15, no. 3, pp. 219-226, 2005.

[13] N. Liu, C. Liu, Y. Xia, and B. Da, "Examining the coordination between urbanization and eco-environment using coupling and spatial analyses: a case study in China," Ecological Indicators, vol. 93, pp. 1163-1175, 2018.

[14] Y. Li, Y. Li, Y. Zhou, Y. Shi, and X. Zhu, "Investigation of a coupling model of coordination between urbanization and the environment," Journal of Environmental Management, vol. 98, pp. 127-133, 2012.

[15] T. Shi, S. Y. Yang, W. Zhang, and Q. Zhou, "Coupling coordination degree measurement and spatiotemporal heterogeneity between economic development and ecological environment-empirical evidence from tropical and subtropical regions of China," Journal of Cleaner Production, vol. 244, pp. 1-11, 2020.

[16] Y. Fan, C. Fang, and Q. Zhang, "Coupling coordinated development between social economy and ecological environment in Chinese provincial capital cities-assessment and policy implications," Journal of Cleaner Production, vol. 229, pp. 289-298, 2019.

[17] E. C. M. Hui, Y. Wu, L. Deng, and B. Zheng, "Analysis on coupling relationship of urban scale and intensive use of land in China," Cities, vol. 42, pp. 63-69, 2015.

[18] J. Liu, X. Jin, W. Xu et al., "Spatial coupling differentiation and development zoning trade-off of land space utilization efficiency in eastern China," Land Use Policy, vol. 85, pp. 310327, 2019.

[19] J. F. Yuan, Z. F. Bian, Q. W. Yan, and Z. Y. Gu, "Coupling coordination degree of urban land use efficiency in typical mining cities in western China," Journal Of Ecology And Rural Environment, vol. 34, no. 8, pp. 709-716, 2018.

[20] Z. P. Wang, C. L. Shi, Q. Li, and G. Wang, "Coupling trending analysis about urbanization and urban resource in Beijing," Energy Procedia, vol. 5, pp. 1589-1596, 2011.

[21] H. Zhang, Z. Wang, J. Liu, J. Chai, and C. Wei, "Selection of targeted poverty alleviation policies from the perspective of land resources-environmental carrying capacity," Journal of Rural Studies, 2019, In press.

[22] J. Chai, Z. Wang, and H. Zhang, "Integrated evaluation of coupling coordination for land use change and ecological security: a case study in Wuhan city of Hubei province, China," International Journal of Environmental Research and Public Health, vol. 14, no. 11, p. 1435, 2017.

[23] J. Chen, Z. Li, Y. Dong, M. Song, M. Shahbaz, and Q. Xie, "Coupling coordination between carbon emissions and the 
eco-environment in China," Journal of Cleaner Production, vol. 276, Article ID 12, 2020.

[24] R. Wang, J. Cheng, Y. Zhu, and P. Lu, "Evaluation on the coupling coordination of resources and environment carrying capacity in Chinese mining economic zones," Resources Policy, vol. 53, pp. 20-25, 2017.

[25] M. Tomal, "Analysing the coupling coordination degree of socio-economic-infrastructural development and its obstacles: the case study of polish rural municipalities," Applied Economics Letters, pp. 1-6, 2020.

[26] Q. Wang, Z. Mao, L. Xian, and Z. Liang, "A study on the coupling coordination between tourism and the low-carbon city," Asia Pacific Journal of Tourism Research, vol. 24, no. 6, pp. 550-562, 2019.

[27] D. Cui, H. Liu, Y. Xiao, N. Cui, J. Liu, and D. Wu, "Spatiotemporal evolution and the driving forces of the coupling coordination degree between urbanization and urban residents' livelihood level in Mongolia," Sustainability, vol. 11, no. 3, p. 781, 2019.

[28] R. Zhang, G. Jiang, and Q. Zhang, "Does urbanization always lead to rural hollowing? assessing the spatio-temporal variations in this relationship at the county level in China 20002015," Journal of Cleaner Production, vol. 220, pp. 9-22, 2019.

[29] Y. Cui and Y. Sun, "Social benefit of urban infrastructure: an empirical analysis of four Chinese autonomous municipalities," Utilities Policy, vol. 58, pp. 16-26, 2019.

[30] J. Wang, Y. Ren, L. Shen, Z. Liu, Y. Wu, and F. Shi, "A novel evaluation method for urban infrastructures carrying capacity," Cities, vol. 105, p. 102846, 2020.

[31] H. Sun, F. Zhen, T. Lobsang, and Z. Li, "Spatial characteristics of urban life resilience from the perspective of supply and demand: a case study of Nanjing, China," Habitat International, vol. 88, p. 101983, 2019.

[32] Y. Liu, S. Lu, and Y. Chen, "Spatio-temporal change of urbanrural equalized development patterns in China and its driving factors," Journal of Rural Studies, vol. 32, pp. 320-330, 2013.

[33] Y. Liu, X. Zhang, X. Kong, R. Wang, and L. Chen, "Identifying the relationship between urban land expansion and human activities in the Yangtze river economic belt, China," Applied Geography, vol. 94, pp. 163-177, 2018.

[34] H. Han and H. Li, "Coupling coordination evaluation between population and land urbanization in Ha-Chang urban agglomeration," Sustainability, vol. 12, no. 1, p. 357, 2020.

[35] J. Li, H. Zhang, and Z. Sun, "Spatiotemporal variations of land urbanization and socioeconomic benefits in a typical sample zone: a case study of the Beijing-Hangzhou Grand Canal," Applied Geography, vol. 117, p. 102187, 2020.

[36] S. J. Wang, Z. T. Liu, T. T. Zhang, J. Y. Wei, and F. Z. Huang, "The coupling relationship between multi-dimensional urbanization and the service industry: a case study of Guangzhou (in Chinese)," Tropical Geography, vol. 39, no. 3, pp. 450-460, 2019.

[37] N. Gao, Y. F. Ma, T. S. Li, and K. Bai, "Study on the coordinative development between tourism industry and urbanization based on coupling model: a case study of Xi'an (in Chinese)," Tourism Tribune, vol. 28, no. 1, pp. 62-68, 2013.

[38] Z. F. Wang and H. Yu, "Study on coupling development between development of tourism industry and small town construction in Zhangjiajie city (in Chinese)," Economic Geography, vol. 32, no. 7, pp. 165-171, 2012.

[39] L. Cheng and J. Zhang, "Assessment of coupling coordination between tourism development and economic growth after the 2008 Wenchuan earthquake: beichuan, China," Asia Pacific Journal of Tourism Research, vol. 25, no. 6, pp. 592-609, 2020.
[40] Y. C. Sheng and Z. P. Zhong, "Study on the coupling coordinative degree between tourism industry and regional economy (in Chinese)," Tourism Tribune, vol. 24, no. 8, pp. 23-29, 2009.

[41] Z. Tang, "An integrated approach to evaluating the coupling coordination between tourism and the environment," Tourism Management, vol. 46, pp. 11-19, 2015.

[42] Z. F. Wang, F. F. Huo, and S. Xu, "Coupled development and regional differences between tourism industry and tourism environments in Hunan, Hubei, Chongqing and Guizhou (in Chinese)," Economic Geography, vol. 38, no. 8, pp. 204-213, 2018.

[43] P. Tapio, "Towards a theory of decoupling: degrees of decoupling in the EU and the case of road traffic in Finland between 1970 and 2001," Transport Policy, vol. 12, no. 2, pp. 137-151, 2005.

[44] N. Van Truong and T. Shimizu, "The effect of transportation on tourism promotion: literature review on application of the computable general equilibrium (CGE) model," Transportation Research Procedia, vol. 25, pp. 3096-3115, 2017.

[45] S. Chen, J. Xi, M. Liu, and T. Li, "Analysis of complex transportation network and its tourism utilization potential: a case study of Guizhou expressways," Complexity, vol. 2020, Article ID 1042506, 22 pages, 2020.

[46] C. Y. Shi, C. S. Zhou, and B. Yu, "The coupling and coordinating analysis between aiding and urbanization in Tibet Autonomous Region (in Chinese)," World Regional Studies, vol. 27, no. 3, pp. 42-54, 2018.

[47] W. M. Xie, D. H. He, and Y. Cao, "A study on the origin, evolution, and system of support for Tibet (in Chinese)," Ethno-National Studies, vol. 2, pp. 15-25, 2014.

[48] M. H. Yang and J. X. Liu, "The system of provinces-cities' complementary counterpart assistance to Tibet and an analysis of its evolution (in Chinese)," Journal of Ethnology, vol. 10, no. 1, pp. 1-11, 2019.

[49] X. Y. He, "Comments on the theoretical contribution and active exploration by the first generation of collective leadership with Mao Zedong as the core towards the mechanism of aiding Tibet (in Chinese)," Tibetan Studies, vol. 4, pp. 3-13, 2012.

[50] Y. H. Song, "Tibet: support from the central government and help from all over the country (in Chinese)," Contemporary China History Studies, vol. 15, no. 4, pp. 12-21, 2008.

[51] X. Y. He, "The formation, development, improvement and application of the mechanism of aiding Tibet (in Chinese)," Tibetan Studies, vol. 6, pp. 2-14, 2012.

[52] X. H. Li, "The Aid-for-Tibet drive and the changes in Tibetan economy and society over the past 50 years (in Chinese)," Journal Of Central University For Nationalities (Philosophy And Social Sciences), vol. 27, no. 5, pp. 70-78, 2000.

[53] G. Liu and L. Shen, "Characteristics and mechanism of Tibet's industrial structure evolution from 1951 to 2004 (in Chinese)," Acta Geographica Sinica, vol. 62, no. 4, pp. 364-376, 2007.

[54] P. Chen, "The influence of the central supply model on the evolution of dual economic structure since the democratic reform in Tibet and its suggestions (in Chinese)," Tibetan Studies, no. 2, pp. 86-93, 2019.

[55] T. W. Zhang and M. J. Luo, "Research on counterpart assistance and promotion of self-development capacity in Tibetan Area (in Chinese)," Guizhou Ethnic Studies, vol. 37, no. 4, pp. 170-174, 2016.

[56] X. L. Tian, "Effect evaluation and policy recommendations of counterpart sssistance capital input for south-central area in 
Xizang tourism economy development (in Chinese)," Resource Development \& Market, vol. 33, no. 1, pp. 105-109, 2017.

[57] X. L. Tian, "Effect evaluation of counterpart assistance provinces capital input for Xizang tourism economy development (in Chinese)," Journal Of Xizang Minzu University (Philosophy And Social Sciences Edition), vol. 37, no. 6, pp. 30-34+154, 2016.

[58] Y. F. Niu, "Tourist resources and tourism development in Tibet (in Chinese)," Resources Science, vol. 24, no. 2, pp. 31-36, 2002.

[59] S. L. Xu, "Fourteen problems facing to the tourism of Tibet (in Chiense)," China population, Resources and Environment, vol. 11, no. 1, pp. 87-91, 2001.

[60] C. Chen, Z. Hu, J. Wang, and J. Jia, "Dynamic surface subsidence characteristics due to super-large working face in fragile-ecological mining areas: a case study in shendong coalfield, China," Advances in Civil Engineering, vol. 2019, Article ID 1576292, 16 pages, 2019.

[61] C. M. Zhu, X. L. Zhang, K. Wang, S. F. Yuan, and M. Skitmore, "Urban-rural construction land transition and its coupling relationship with population flow in China's urban agglomeration region," Cities, vol. 101, pp. 1-10, 2020.

[62] Y. Geng, Y. Tan, H. Zhang, and M. Maimaituerxun, "Measurement and prediction: coupling coordination of finance and air environment," Discrete Dynamics in Nature and Society, vol. 2020, Article ID 1406978, 12 pages, 2020.

[63] L. Xing, M. Xue, and M. Hu, "Dynamic simulation and assessment of the coupling coordination degree of the economyresource-environment system: case of Wuhan city in China," Journal of Environmental Management, vol. 230, pp. 474-487, 2019.

[64] Y. Sun, S. Liu, Y. Dong et al., "Spatio-temporal evolution scenarios and the coupling analysis of ecosystem services with land use change in China," Science of The Total Environment, vol. 681, pp. 211-225, 2019.

[65] W. Liu, F. Jiao, L. Ren, X. Xu, J. Wang, and X. Wang, "Coupling coordination relationship between urbanization and atmospheric environment security in Jinan City," Journal of Cleaner Production, vol. 204, pp. 1-11, 2018.

[66] Y. Sun, Y. Cui, and H. Huang, "An empirical analysis of the coupling coordination among decomposed effects of urban infrastructure environment benefit: case study of four Chinese autonomous municipalities," Mathematical Problems in Engineering, vol. 2016, Article ID 8472703, 11 pages, 2016. 